\title{
Burladores y burlados en la literatura ejemplar de España Edad Media
}

Graciela Cándano Fierro

\begin{abstract}
Doctora en Letras Españolas
por la Universidad Nacional

autónoma de México (UNAM).

Investigadora en el área de

literatura ejemplar de los siglos

XII al XIV. Docente de Literatura

Española Medieval y Seminario

de Literatura Medieval Española

en el Colegio de Letras

Hispánicas de la Facultad de

Filosofía y Letras de la UNAM.
\end{abstract}

Contacto: candanogj@gmail.

com 
CARACOL 3 / VÁRIA

Palabras clave: Edad Media

en España; literatura ejemplar;

risa; universalidad de lo cómico.

KEYWORDS: Spanish Middle

Ages; exemplary literature;

laughter; universality of humor.
RESUMEN: En este artículo hago un breve recuento

de los motivos cómicos que aparecen en algunas

colecciones de exempla medievales, por ejemplo

Disciplina clericalis y el Conde Lucanor, tocando aunque

sea someramente una obra híbrida, como es el Libro

de Buen amor, del Arcipreste de Hita. El designio de

estas obras de enseñar y moralizar a los auditorios

se hace patente desde el preámbulo de cada una, en

cambio, los respectivos autores o recopiladores jamás

señalan en sus introducciones que el divertir y menos

hacer reír o reinterpretar o descontextualizar sea el

propósito de sus relatos. El eje de mi rastreo consiste

en orientar el análisis de las obras ejemplares hacia la

revelación de su parte divertida y, de ser posible, cómica.

He basado mi análisis en una estructura conceptual

surgida del estudio de teóricos de renombre en relación

al fenómeno de la risa (Aristóteles, Bergson, Freud,

Ducrot, entre otros).El objetivo que me propongo es

mostrar la universalidad de la comicidad de esas obras,

misma que ha llegado hasta nuestros días.

ABSTRACT: This article presents a brief account of

comical motifs that appear in some medieval exempla

collections, for instance the Disciplina clericalis and

Conde Lucanor, with an approximation to a hybrid work,

as Libro de Buen amor, by the Arcipreste de Hita. The

purpose of these writings was to teach and moralize 
Graciela Cándano Fierro

\author{
audiences and this is notable from the very introduction \\ on. However, authors or compilers never include in \\ their preliminaries that the purpose of their writings \\ is to amuse, make their readers laugh, reinterpret or \\ decontextualize the world. The main objective of this \\ investigation is to direct the analysis of exemplary \\ works toward revealing their amusing or even comical \\ side. Central to this study is a conceptual structure \\ of the laughter phenomenon that has come forward \\ from theoretical works by well-known authors such \\ as Aristotle, Bergson, Freud, Ducrot and others. The \\ subject matter is to emphasize the universality of the \\ comical vein in the aforesaid writings, which has lasted \\ up to the present.
}


ARACOL 3 / VÁRIA

e porque de buen seso non puede omne reír,

avré algunas burlas aquí a enxerir"

Libro de Buen Amor

EN EL SIGLO XIII las letras hispanas se distinguieron por sus contenidos altamente didácticos, dado el afán de enseñanza, de aleccionamiento, que envolvía a la época. La didáctica novelesca, en particular, está conformada por recopilaciones de imaginativos cuentos -que rebasan ampliamente la expresión doctrinal-, cuya efectividad radicó en la fuerza persuasiva de sus relatos, en la capacidad que pudiera tener cada uno de ellos para instituirse en un verdadero ejemplo.

De hecho, tanto los cuentos -con su respectiva moraleja aflorando al finalcomo las fábulas, las anécdotas, los relatos piadosos o los milagros, fueron utilizados con el ánimo de edificar al hombre del Medioevo. Todos los géneros narrativos mencionados (cuento, fábula, etc.) y todas las influencias (bíblicas, hagiográficas, greco-latinas y orientales) pasaron a formar parte de este tipo singular de didáctica novelesca: las colecciones de exempla. ${ }^{2}$

Ahora bien, los personajes de los relatos ejemplares (exempla) que sin duda cumplían una función moralizante y que a su vez eran utilizados por los compiladores y predicadores para advertir, intimidar, o prohibir alguna conducta, bien pudieron haber sido percibidos por el público receptor como personajes

I Debe destacarse que la práctica de recolectar sententiae y exempla se inició en el período clásico latino. Sin embargo, dicha práctica se vio poderosamente incrementada durante la Baja Edad Media, en virtud de que el cristianismo modificó substancialmente la naturaleza del exemplum al extraerlo del ámbito del derecho procesal en que nació (Deyermond, Historia de la literatura española. La Edad Media, I76).

2 Para mayor información sobre la especificidad de este género literario remito al lector a Cándano, Estructura, desarrollo y función de las colecciones de exempla en la España del siglo XIII, II-57. 
Burladores y burlados en la literatura ejemplar de España Edad Media

Graciela Cándano Fierro

divertidos, truhanescos, histriónicos y cómicos. ${ }^{3}$ Y ello a pesar de que ya desde los siglos VIII y IX, teóricamente, los moralistas prohibían a los cristianos escuchar narraciones cómicas, pues éstas eran consideradas estériles y despreciables. ${ }^{4}$

Esto último es importante de señalar porque, paradójicamente, las órdenes de predicadores errantes terminaron formando parte de las actividades de la calle, la plaza, el sendero, es decir, del ámbito espacial del mundo del juglar, a tal grado que los primeros franciscanos, observa Paul Zumthor, 5 fueron tratados de bufones. Los sermones se introducían por medio de la célebre muletilla "Oíd buena gente”, para enseguida hacer gala de las técnicas que suponían un determinado dominio de la voz, del gesto y del aspecto exterior. El éxito de los predicadores se hace patente en la siguiente semblanza presentada por Johan Huizinga:

El hermano Ricardo, predicador popular, predicó, en I429, en París, diez días sucesivos. Hablaba desde las cinco hasta las diez u once de la mañana en el cementerio de los Inocentes [...]. Cuando después de su décimo sermón anunció que era el último [...] los ricos y los pobres lloraban $[. .$.$] hondamente. ^{6}$

3 El hombre de la Edad Media era susceptible de experimentar estupefacción e iluminismo, postración y exaltación, melancolía y arrebato. "No hay más que contemplar los manuscritos ilustrados, miniados, de los siglos XIII y XV o las pinturas, las ornamentaciones arquitectónicas de las iglesias. Junto a escenas piadosas hay obras como de pesadilla, alucinantes, demenciales... Por todos los resquicios se cuelan diablos, volantineros, saltimbanquis con sus trucos y acrobacias. Lo piadoso y lo grotesco van siempre de la mano" (Maldonado Arenas. Religiosidad popular, 226).

4 “La sociedad medieval, temerosa de la fuerza de transformación de lo cómico, controla la risa legalizándola en determinadas circunstancias y en fechas precisas (fiestas de carnaval, de locos, etc) donde la colectividad podía libremente, a través del lenguaje profanatorio y de las bufonadas, abolir el mundo social y opresor y, saliendo de él -aunque fuera a corto plazo- crear un mundo invertido, universal, fuera de la jerarquización...” (Rodríguez García. "La rosa que tiene nombre”, s/p).

5 Zumthor, La letra y la voz, 9I.

6 Huizinga. El otoño de la Edad Media, I8. 
Desde luego que a los exempla, aparte de tener la función de amenizar las -con frecuencia -áridas lecciones morales, nunca se les dio la atribución de provocar verdadera hilaridad en el auditorio ni, menos aún, como explica Robert Detweiler, la de desacralizar los contenidos serios de los sermones.7

Por su parte, María Jesús Lacarra señala que la general sobriedad de la literatura española de la Baja Edad Media "contrasta con la riqueza de la francesa, con sus farsas, fabliaux, simulacros grotescos de canciones de gesta, etc."; y resalta que, además de ser escasos los textos risueños, hay muy pocos trabajos críticos sobre este aspecto oculto de las letras españolas. ${ }^{8}$ El sentido de "oculto" es muy atinado, tanto por el hecho de que es factible encontrar cierta comicidad en donde menos se espera -y que se asoma involuntariamente en algunos cuentos o exempla de tendencia seria y hasta trágica-, como porque existen relatos ciertamente cómicos, de la tradición oral o escrita, encubiertos por el lenguaje didáctico propio de una colección de exempla.

La literatura didáctica vio la luz en obras de consulta y predicación escritas por clérigos para clérigos, como es el caso de la Disciplina clericalis (siglo XII). 9 Por otra parte, ya en el siglo XIV, surgen seglares que escriben este tipo de obras para seglares: don Juan Manuel y su Libro de Patronio o El Conde Lucanor, ${ }^{\text {Io }}$ que instruye a individuos menos doctos que el autor, y finalmente

7 Apud Goldberg. "Sexual humor in misogynist medieval exempla”, 70.

8 Lacarra. "Elementos cómicos en los cuentos medievales castellanos", 32.

9 Fue la primera colección de exempla que se compiló en España. Obra escrita en latín por un judío converso, Pedro Alfonso (h. Io62), quien vivió en Inglaterra y llegó a ser médico de Enrique I. La Disciplina clericalis está constituida por 34 exempla, salpicados de múltiples sententiae; y se estructura dentro de un tenue encuadramiento narrativo en el que un padre instruye a su hijo por medio de ejemplos. Gozó de gran popularidad tanto en España como en el resto de Europa ( $C f$. Deyermond, Historia de la literatura española, I77).

Io Obra cumbre de la cuentística medieval, cuyo autor, el infante don Juan Manuel (I282-I348), fue sobrino del rey Alfonso X el Sabio, y digno representante de la aristocracia de la época. La obra, escrita con diestrísima mano, consta de 5I ejemplos, encuadrados en el marco consabido de un maestro que instruye a su discípulo: Patronio -el privado- aconseja a su señor Lucanor en las dificultades que le impone su estado ( $C f$. Deyermond, Historia de la literatura española, 24I-243). 
Burladores y burlados en la literatura ejemplar de España Edad Media

Graciela Cándano Fierro

se escribirán libros donde el elemento de diversión llega a eclipsar el propósito didáctico. ${ }^{\text {II }}$

El ensamble de adoctrinamiento y comicidad no nulifica, sino por el contrario, confirma el poder de transmitir un mensaje de índole didáctica, pues -como veremos más adelante- la risa tiene aquí un valor sancionador.

Por simple lógica podemos suponer que el origen de la risa puede encontrarse en innumerables aspectos relacionados con lo humano, ya sea en la Antigüedad, el Medioevo o los tiempos modernos: una silueta bufonesca, un ademán extravagante, una frase de doble sentido, una vergonzosa distracción o una situación absurda. Ante una narración, tanto la descripción de figuras, la insinuación de gestos o los juegos de palabras, como las actitudes de los personajes, las sutilezas o las coyunturas del argumento pueden pasar ante nuestra imaginación como testimonios de lo cómico en una variedad que se antoja infinita. ${ }^{\mathrm{I}}$

Para que los protagonistas de una situación dada -o la persona-objeto mismamuevan a risa, no deben producir compasión en el receptor. De este modo, serán cómicos los personajes bobos, torpes o ingenuos, ${ }^{13}$ ridículos y absurdos..., por lo que podremos sondear la comicidad de los exempla sin excesivo riesgo de hacerlo con una mentalidad "moderna", desviada o sofisticada.

Como elemento clave para determinar la comicidad de los exempla recurriré a las nociones que devienen de la comedia. Hay un efecto cómico cuando:

II Lacarra. "Elementos cómicos en los cuentos medievales castellanos", 32.

I2 Cf. Cándano, La seriedad y la risa, donde se profundiza en todos estos elementos cómicos a partir de una gran variedad de exempla que se hallan insertos en Disciplina clericalis, Calila e Dimna, Sendebar, Libro de los enxemplos por $A B C$, Libro de los gatos, entre otros.

I3 Las obras cómicas que se representaban en las plazas públicas de la Edad Media hacían del tonto, del ingenuo y del torpe, algunos de sus personajes predilectos. Por no referirme al Carnaval, donde esto era más que obvio.

228 
i) el personaje principal ostenta una conducta torpe, viciosa, ridícula, perversa o funesta que afecta a quienes le rodean (Bajtín, I974);

ii) la acción la comete un personaje innoble, inferior, repulsivo, que el espectador de la comedia identifica con alguien de su entorno al que repudia o desprecia;

iii) por ello el receptor se percibe superior a la torpe o mala conducta del personaje y no siente compasión por sus irrisorias fallas;

iv) el placer del espectador proviene de que disfruta de la desgracia del personaje y lo escarnece con la risa,

v) esa risa que provoca el personaje es el medio con el que la sociedad castiga a quien se porta mal o viola las reglas de la vida cotidiana.

Siempre y cuando nos despojemos -o nos despojen hábilmente- de los sentimientos de afecto y piedad, y se presenten las combinaciones adecuadas, nos podrán hacer reír con sus actos el bobo, el despistado, el genio, o el sabihondo... y como ellos, miles más.

El umbral entre el drama -y áun la tragedia- y la comedia es sutil. De hecho, todo nos puede hacer reír según el entorno en que estén envueltos el protagonista y el receptor del cuento, anécdota, film o pieza teatral. Así, mientras la avaricia de Ebenezer Scrooge (de Dickens) es odiosa, ${ }^{\text {T4 }}$ la de Harpagón (de Molière) es cómica. Y hasta virtudes como la pureza pueden resultar jocosas.

En primer lugar, siguiendo a Bergson, concuerdo con que uno de los dos grandes fenómenos que producen situaciones cómicas, son las condiciones señaladas en el automatismo. Las causas más importantes de los comportamientos mecánicos son las ideas fijas, las obsesiones, las manías, los traumas,

I4 Este personaje central de "Cuento de Navidad" es un 'squeezing, wrenching, grasping, scraping, clutching, covetous old sinner' (apud The Century Cyclopedia of Names, 912); es decir, es un pecaminoso viejo despótico, retorcido, avaro, cascarrabias, porfiado y codicioso. 
Burladores y burlados en la literatura ejemplar de España Edad Media

Graciela Cándano Fierro

la locura y la inconsciencia de sí mismo, por una parte; por otra, tenemos también como productoras más frecuentes de inercias la vanidad, la ignorancia, la ingenuidad, y la fatuidad.

Ahora bien, para Bergson existe otro fenómeno tan trascendente como el automatismo: la excentricidad (estar fuera del centro). Para comprender este concepto, orientaré el análisis en los siguientes términos:

Para poder sobrevivir sin demasiados sobresaltos, la cotidianidad nos obliga a vivir atentos a lo que nos rodea, así como a adaptarnos -con la ductilidad que nos permitan nuestros propios límites y los que impone la sociedad- a las diversas circunstancias por las que atravesamos en la vida. ${ }^{\text {I5 }}$

Lo que nos mueve a risa es lo caricaturesco del aspecto de los personajes o lo mecánico de sus movimientos o actitudes, así como también lo ridículos, distraídos, descabellados o absurdos, desmesurados, torpes, cándidos, viciosos o fanfarrones que puedan ser. De este modo, los protagonistas de las obras didácticas seleccionadas que presenten estas condiciones serán juzgados cómicos. Ahora me centraré en el binomio burlador/burlado.

\section{Personajes cómicos en el corpus}

Del universo de personajes cómicos encontrados en los exempla de la Disciplina Clericalis y de El Conde Lucanor, he seleccionado una mínima muestra, en donde se presentan una o más de las características mencionadas: ${ }^{16}$

I5 Toda rigidez de carácter, toda rigidez del espíritu y áun del cuerpo será, pues, sospechosa para la sociedad, porque puede ser indicio de una actividad que se adormece y de una actividad que se aísla, apartándose del centro común, en torno al cual gravita la sociedad entera ( $C f$. Bergson. La risa, 54).

I6 He detectado dieciséis relatos cómicos en la Disciplina y diez en El Conde Lucanor; pero para fines de este trabajo -y por cuestiones de espacio- sólo me referiré a un exemplum de cada una de las citadas obras. María Jesús Lacarra ha encontrado otros elementos que provocan risa en algunos de los ejem- 
El "ejemplo del ladrón y el rayo de luna" (Disciplina XXIV, p. 83-84) narra cómo un ladronzuelo cae en la trampa que le tiende el dueño de la casa que pretende robar. Lo cómico está en la manera como se desencadenan los hechos: El inexperto gerifalte deja sentir sus pasos en el tejado, lo que pone en alerta al señor, y éste fingiendo haber sido un exitoso asaltante alardea en voz alta que su riqueza proviene de la estrategia que empleaba para cometer sus hurtos, colgándose de un rayo de luna y repitiendo siete veces la palabra "saluem", ${ }^{17}$ entraba por la ventana sin peligro, "arramblaba" con todo lo de valor y de la misma manera salía. El cándido ladrón sigue paso a paso las acciones que escucha contar al amo de la casa; y repitiendo la fórmula mágica, "cogió con la mano un rayo de luna, soltó manos y pies y cayó por la ventana adentro de la casa, haciendo gran ruido" (83). Además de romperse pierna y brazo, recibió su merecido por fiarse de 'palabras falaces'. En efecto, el ardid consiste en una mentira increíble, con la que el propietario, además de evitar el robo, pone en evidencia la capacidad no tanto física como mental del crédulo ladrón.

En la literatura cómica -dice Ménard (1983) - el lector se divierte placenteramente a costillas de los personajes inhábiles o torpes, ya que le es fácil jactarse de ser superior a ellos. ${ }^{18}$ Efectivamente, el protagonista de slapsticks (golpes, accidentes, pastelazos, etc., productos de su chambonería) es uno de los personajes más sencillos y frecuentes en cualquier tipo de circunstancia risible. Es torpe un individuo cuando por su ineptitud se hace daño físico involuntariamente; cuando por su inhabilidad todo lo que trata de hacer le sale mal; etc.

plos que comento en este trabajo, pero no me detendré en ellos, pues aquí me interesa la caracterización de los personajes cómicos. Remito a sus interesantes artículos consignados en la Bibliografía final.

I7 La palabra "saulem" puede tener conexión con "sullam", en hebreo, escalera. (Lacarra. Pedro Alfonso, I25).

I8 Les fabliaux. Contes à rire du moyen âge, I80. 
Burladores y burlados en la literatura ejemplar de España Edad Media

Graciela Cándano Fierro

Y aunque la enseñanza que pretende dar el narrador de este cuento a su hijo es clara: "No des fe a todo consejo que oigas hasta que no esté probada su utilidad" (82), y más adelante el filósofo diga "Guárdate del consejo ázimo hasta que esté fermentado” (84), surge la risa tranquilizadora ante el orden restaurado, quedando en la memoria el ejemplo del jescandaloso! y supuestamente lícito castigo al fatuo ladrón.'99

El enxemplo titulado "De lo que contesçió a un raposo con un cuervo que teníe un pedaço de queso en el pico" (El Conde Lucanor V, 77-8I) es una recreación de la conocida fábula del zorro que engaña al cuervo con la finalidad de apropiarse del pedazo de queso que esa ave tenía en el pico.

Lo cómico de este relato estaría más que en la treta de la astuta vulpeja, en la forma como se va 'inflando el ego' del cuervo que, convencido de que su "prietura" se semeja en las plumas al pavo real y a la gacela en los ojos, acaba -embelesado consigo mismo- creyendo que posee una hermosa voz: "E desque el pico fue avierto para cantar, cayó el queso en tierra, et tomólo el raposo et fuése con él; et así afinco engañado el cuervo del raposo, creyendo que avía en sí más apostura et más cumplimiento de quanto era la verdat" (p. 80); y ello a pesar de que el socarrón zorro le había anunciado: "vos diré las cosas en que las gentes tienen que no sodes tan apuesto" (79). Es precisamente esa "verdad engañosa" la que lleva al cuervo caer en un engaño increíble.

Sólo los demasiado tontos o desquiciados por algún problema psíquico pueden caer en interferencias provocadas por mentiras o engaños a todas luces fuera de razón. Siempre hay cierta justificación para que el engañabobos se arriesgue a mentir o pretenda embromar al otro de manera tan desfachatada, así como un grado de ingenio en su argucia, pero la clave de este equívoco está

I9 Es evidente el grado de placer y risa socarrona que provoca ver cómo el victimario acaba convertido en víctima. 
en la sandez o extravío del engañado. En tal tenor, cabe la observación de Johan Huizinga, en el sentido de que la categoría de lo cómico está estrechamente vinculada con el desatino, el desvarío, el frenesí, la "locura" (the folly). ${ }^{2 \circ}$

La intención didáctica de este memorable exemplum -expresada en los dísticos de don Johan- es contundente: Qui te alaba lo que non es en ti,/ sabe que quiere levar lo que as de ti (81).Pero cabe preguntarse si las palabras de Patronio no encierran una sutil ironía que deja entrever que el cuervo queda no solamente engañado por las "palabras fermosas" del raposo, sino también denigrado al no estar consciente de su propia naturaleza, dado que "siempre las sus razones -del embustero zorro- fueron con verdat". ${ }^{21}$ En otras palabras, esa "verdat engañosa" acarrea pérdida material, pero sobre todo escarnece a la víctima por preciarse de lo que no es. El despojo merecido a causa del engreimiento del cuervo conduce, entonces, a la risa reprobatoria. ${ }^{22}$

Janko me lleva al pensamiento aristotélico, del que extraigo el principio de que uno de los caracteres típicos de la comedia es el del individuo que fanfarronea; ${ }^{23}$ es el personaje cómico que alardea de lo que, muy posiblemente, carece... y que queda frecuentemente en evidencia. Son fanfarronas las personas jactanciosas que se creen más fuertes, valientes, bellas, seductoras, inteligentes, talentosas, sabias, etc., etc., de lo que en realidad son.

Detengámonos -aunque sólo sea de paso- en el pasaje, por todos conocido, de la "Disputa de los griegos y de los romanos" (estr. 44-64) incluido en el

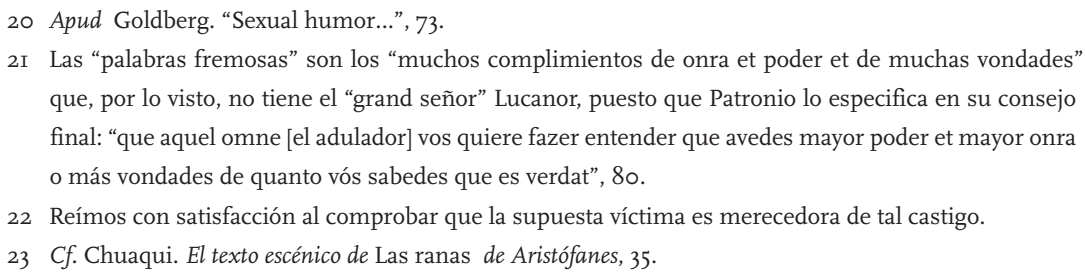


Burladores y burlados en la literatura ejemplar de España Edad Media

Graciela Cándano Fierro

Libro de Buen Amor del Arcipreste de Hita, ${ }^{24}$ cuyos protagonistas, debido a sus diferentes idiomas pactan contender por medio de señas para decidir si los romanos son merecedores de las leyes; y se nombra para ello a un exquisito doctor griego y a un bellaco y pícaro romano. ${ }^{25}$ Una vez finalizado el debate, en la mente del griego aparece la imagen de un romano sabio. Y a la inversa, considera el romano estar ante un bravucón como él. El primero se refiere a Dios y la Santísima Trinidad y el segundo a "partirle la cara" al emisor. Tal parece que la función de las señas no consiste en expresar la verdad, sino en servir de mediadoras para la supuesta comunicación, ${ }^{26}$ pues mientras que los romanos no entienden las señas del griego y responden instintivamente, los griegos creen que sí entienden la "virtud" de los romanos. El caso es que de tan

24 Obra escrita hacia mediados del siglo XIV, considerada como una de las obras maestras de la literatura castellana medieval, y atribuida a un tal Juan Ruiz, arcipreste de Hita. Es una miscelánea de géneros literarios, donde tienen cabida principal los exempla; libro heterogéneo en el que predominan la técnica de la parodia, así como el tono irónico y sobre todo la ambigüedad. Todo ello hace difícil definir con exactitud el propósito del arcipreste (Cf. Deyermond. Historia de la literatura, I89-207).

25 La disputa comienza con el griego levantando el dedo índice, a lo que el romano le responde tendiendo hacia el griego el pulgar y los dedos contiguos en forma de arpón. El doctor griego se levanta y extiende la palma de la mano, y el bellaco enarbola su puño cerrado. Entonces, el sabio griego anuncia a su pueblo que los romanos sí son dignos de sus leyes, y se las entrega. Después, sus respectivos bandos preguntan al griego y al romano qué han significado todas aquellas señas... El griego aclara a los suyos que primero señaló que había un solo Dios y que el romano le contestó que había uno, pero en tres personas. Que el signo que le hizo después al romano significaba que todo estaba sometido a la voluntad de Dios, y que éste le contestó que lo tenía en su poder, demostrando con todo ello merecer, por su sabiduría, las leyes de los griegos. Mientras tanto, el romano declara a sus rudos compañeros que primero el griego lo amenazó con que le sacaría un ojo, ante lo cual él le respondió que le saltaría los dos ojos y los dientes. Y que por último el griego hizo evidente que le daría una bofetada, por lo que el pícaro le hizo seña de darle un feroz puñetazo. El romano concluye diciendo que, por temor a su fiereza el griego terminó el pleito y les dieron las leyes ( $C f$. Cándano. La seriedad y la risa, I33).

26 Lo mismo sucede con las palabras del enamorado: "palabras cuya función no es la de expresar un sentimiento, sino la de servir de mediadoras del deseo" (Bandera. "La ficción de Juan Ruiz", 506) 
grandes equívocos se desprende y queda un hecho irreversible y tangible: los romanos poseen las leyes.

Más allá de todos los trascendentes significados que tiene el exemplum de Juan Ruiz, ${ }^{27}$ mi análisis - que proviene de vertientes distintas a la de Bergsonentronca y se engarza con lo que éste ha definido como interferencia. ${ }^{28}$ No se trata de una lucha de saberes, no es tampoco un intento de trampa o engaño. Es un "inocente" contraste de los griegos y su largo estudio y conocimiento frente a la observación de la naturaleza y del corazón humanos por parte de los romanos. ${ }^{29} \mathrm{Ni}$ el griego pretende ser un burlador, ni el romano piensa en burlarse (quizá en vengarse); pero finalmente hay un burlado (griego) y un burlador (romano) en virtud de las circunstancias. ${ }^{30}$

En términos generales, para que haya un burlador y un burlado debe existir un engaño que tenga la finalidad de crear una idea errónea, confusa o inexacta en el burlado. En algunos casos es voluntario -la mayoría-, en otros resulta ser producto de las circunstancias, es decir no voluntario o intencional.

Retomando los dos primeros exempla (de Disciplina clericalis y de El conde Lucanor), es evidente que tanto el dueño de la casa como el raposo, es decir los

27 En este pasaje quiere enseñar el autor que no hay que tomar su libro al pie de la letra, sino de manera "sotil" (Bandera, I973). O también puede estar advirtiendo que quien malinterprete su libro o no lo sepa "tocar" bien, sólo logrará producir un "neçio devaneo".

28 "Es cómica toda situación que pertenece a dos series de hechos absolutamente independientes y que puede ser interpretada contemporáneamente en dos sentidos completamente distintos" (Bergson. 8oa)

29 Me imagino en los mismos términos una discusión entre sabihondos médicos y experimentadas comadronas.

30 En efecto "la sabiduría del doctor griego sale bastante mal parada en la disputa [...] y su solemnidad resulta bastante ridícula. [Mientras que] los romanos demostraron tener mayor sabiduría práctica. [Y las leyes pertenecen a ese orden]. De ahí que la sabiduría del doctor griego sea un tanto ridícula porque está fuera de lugar, porque hay un evidente contraste entre esa manifestación de saber y las circunstancias concretas en que se desarrolla la disputa” (Bandera. “La ficción...”, 498-499). 
Burladores y burlados en la literatura ejemplar de España Edad Media

Graciela Cándano Fierro

burladores, crean intencionalmente la confusión en los burlados. En el tercero, ni el burlador ni el burlado son conscientes de ello. Según Seidennspinner (29), ${ }^{3 \mathrm{I}}$ el griego interpreta los signos literales del romano como figurativos y éste interpreta los signos figurativos del griego como literales. Situación parecida encontramos en el ladrón que interpreta los signos figurativos (forma de robar) del dueño de la casa como literales; y el cuervo hace lo mismo en relación a los elogios del zorro.

Pero recordemos la estrofa del Arcipreste: "bien o mal, qual puntares, tal diré, ciertamente". Así como podemos -los lectores- despreciar o burlarnos de los griegos y también de los romanos, finalmente la ambigüedad triunfa y ni los griegos pierden, ni los romanos son merecedores de las leyes. Ambos son víctimas del mensaje ambiguo del autor: bajo la espina yace la rosa, noble flor.

Y el público puede repudiar al zorro, o al dueño que engaña al ladrón (como lo haría con los burladores del emperador o con los ladrones del rey amante de la alquimia), ${ }^{32}$ pero también puede llegar a despreciar a las víctimas del engaño y finalmente a cuestionar la "doble enseñanza" del autor.

Si bien los personajes que intentan burlarse quedan desprestigiados ante los lectores, podríamos preguntarnos si los narradores que pretenden adoctrinar pueden quedar también ante el lector como ingenuos -a pesar de sus intenciones moralizantes, didácticas-.

Las motivaciones de las actitudes de los protagonistas de algunos exempla, por muy aleccionadoras que parezcan éstas últimas, encierran -como dice

3I Apud Anievas Gamallo. "La crisis de los signos" y "la crisis de la verdad": Ambigüedad y parodias en el Libro de Buen Amor, 29.

32 Cuentos emblemáticos pertenecientes también a El conde Lucanor.

236 
Luigi Amara del aforismo- "la íntima convicción de que el hombre no tiene remedio".33

Esta galería de personajes que hemos analizado presenta un elemento en común que consiste en que todos padecen una ceguera viciosa momentánea, tienen una especie de venda en los ojos que les impide ver la realidad; y es lo que los convierte en cómicos. ${ }^{34}$ Además manifiestan una falla, una mácula, y por ello deben sufrir una corrección por medio de un adecuado castigo. ${ }^{35}$

En el universo didáctico -el de la difusión de los valores del poder eclesiástico y aristocrático para la preservación de ambos- el rebajamiento es un concepto asimilable al de la comedia. Janko (I984), en la reproducción que hace de la parte que Aristóteles dedicó a la comedia en su Poética, nos dice: "la risa surge [...] en el escenario [...] también de rebajar a los personajes". ${ }^{36}$

Es la risa disciplinaria; ${ }^{37}$ la que surge divertida y a la vez es capaz de enmendar -por vía del escarnio- conductas perniciosas producidas por automatismos físicos o psíquicos. Ya que la sociedad no puede reprimir oficialmente a los

33 Amara. "La vibración del aforismo", 9

34 Tal como he expresado anteriormente, los personajes humanos (o de animales, o de bestias humanizadas, cuando es el caso) que constituyen un motivo cómico en sí mismos son los que llenan la condición de ser caricaturescos, ridículos, descabellados, desmesurados, torpes, viciosos, cándidos o fanfarrones.

$35 \mathrm{Al}$ testarudo jorobado (Disciplina VI), al ingenuo cornudo (Disciplina IX), al cándido ladrón (Disciplina XXIV), al vanidoso cuervo (Lucanor V), al ambicioso rey (Lucanor XX), al obsesivo monarca (Lucanor XXXII), etc. Y “en la disputa [de griegos y romanos], la intención de los romanos era buena, la de los griegos torcida a causa de su orgullo de saber. El aspecto providencial de su castigo hay que verlo precisamente en el hecho de que fueron vencidos, burlados, por la absoluta falta de ciencia de un mentecato. [Además...] "se frustra el propósito de los griegos porque éstos no querían desprenderse de las leyes. Si aceptaron la disputa fue sólo 'por se escusar', dando por sentado de antemano la incapacidad de los contrarios" (Bandera, I973).

36 Aristotle on Comedy: Towards a Reconstruction of Poetics II, 93-99.

37 Ya sea ésta sancionadora, correctiva, tranquilizadora, reprobatoria, condenatoria o escarnecedora, como he mencionado en los respectivos relatos. 
Burladores y burlados en la literatura ejemplar de España Edad Media

Graciela Cándano Fierro

inhábiles, abstraídos o cuadriculados, la risa se transforma en un gesto social orientado a perturbar, cuando menos, al personaje irrisorio..$^{38}$

¿Podríamos, entonces, concebir los exempla de nuestro corpus como pequeñas comedias de uno o dos actos, cuyo objetivo es corregir las costumbres representando los errores, vicios o excentricidades del ser humano, como ocurre en la comedia clásica?

\section{REFERENCIAS BIBLIOGRÁFICAS}

Abril, Gonzalo. Comicidad y humor. Terminología científico-social. Buenos Aires: Anthropos, I991. www.ucm.es/info/eurotheo/diccionario/C/comicidadhumor. pdf. (1986)

Amara, Luigi. "La vibración del aforismo". In: SP Revista de Libros, Año II, núm. I8, septiembre 2009, 9 .

Anievas Gamallo, Isabel. "La crisis de los signos" y "la crisis de la verdad": Ambigüedad y parodias en el Libro de Buen Amor. http://faculty.washington.edu/ petersen/lba/anievas.htm, 29.

Bajtín, Mijail. La cultura popular en la Edad Media y el Renacimiento. Barcelona: Barral, 1974.

Bandera, Cesáreo. "La ficción de Juan Ruiz”, JSTOR, PMLA, vol.88, núm.3, I973, 465-510.

38 "El proceso de la comicidad es el de un mal que concita su propio remedio: el de una vacuna social. La noción de 'daño limitado' es común a la teoría aristotélica de la vituperación cómica y a la bergsoniana de la superposición de lo mecánico sobre lo vivo: en ambos casos una pequeña cantidad de mal (sea fealdad o rigidez) provoca la explosión del gozo (sea catártico o correctivo). La comicidad es un procedimiento paradójico que involucra detrimento y reparación, castigo y premio. Es por ello una expresión privilegiada del paradojismo inherente a toda forma de sociabilidad" (Abril. "Comicidad y humor", 3).

238 
Bergson, Henri. Le rire. Essai sur la signification du comique. Paris: Presses Universitaries de France, I956.

Introducción a la metafísica. La risa. México: Porrúa, I986.

Cándano, Graciela. La seriedad y la risa. La comicidad en la literatura ejemplar de la Baja Edad Media. México: Universidad Nacional Autónoma de México/Instituto de Investigaciones Filológicas, 2000 (Bitácora de Retórica, 7)

Estructura, desarrollo y función en las colecciones de 'exempla' en la España del siglo XIII. México: Universidad Nacional Autónoma de México/Instituto de Investigaciones Filológicas, 2009 (Colección de Bolsillo, I3).

Chuaqui, Carmen. El texto escénico de Las ranas de Aristófanes. México: Universidad Nacional Autónoma de México/Instituto de Investigaciones Filológicas, I996 (Cuadernos del Centro de Estudios Clásicos, 43).

Deyermond, Alan D. Historia de la literatura española. La Edad Media. Barcelona: Ariel, I973.

Ducrot, Oswald. Polifonía y argumentación. Cali, Colombia: Universidad del Valle, 1988.

Freud, Sigmund. El chiste y su relación con el inconsciente. Buenos Aires: Amorrotu editores, I979.

Goldberg, Harriet. "Sexual Humor in Misogynist Medieval Exempla", In: Women in Hispanic Literature. Beth Miller (ed.), Los Angeles: University of California Press, 1983, 67-83.

Huizinga, Johan. El otoño de la Edad Media. Madrid: Revista de Occidente, I973.

Janko, Richard. Aristotle on Comedy: Towards a Reconstruction of Poetics II. Berkeley: University of California Press, I984.

Juan Manuel, don. El conde Lucanor. José Manuel Blecua (ed.), Madrid: Castalia, I97I. 
Burladores y burlados en la literatura ejemplar de España Edad Media

Graciela Cándano Fierro

Lacarra, María Jesús. “Elementos cómicos en los cuentos medievales castellanos”, Tigre 6 (Centre d'etudes et recherches hispaniques) Grenoble: University Sthendal, I99I, 3I-47.

. "Cuento medieval y cuento oral: 'La triple tasa' (AT I66I)", Garoza: Revista de la Sociedad Española de Estudios Literarios de Cultura Popular 5, 2005, II9-I38.

- Pedro Alfonso. Zaragoza: Diputación General de Aragón. Departamento de Cultura y Educación, I99I (Los aragoneses, 3).

Maldonado Arenas, Luis. Religiosidad popular. Nostalgia de lo mágico. Madrid: Ediciones Cristiandad, I975.

Menard, Philippe. Les fabliaux. Contes à rire du moyen âge. Paris: Press Universitaries de France, I983 (Littératures Modernes).

Pedro Alfonso. Disciplina clericalis. María Jesús Lacarra y Esperanza Ducay (eds.), Zaragoza: Guara Editorial, I980.

Rodríguez García, Mercedes. “La rosa que tiene nombre”, In: La tecla con café. http://lateclaconcafe.com

Ruíz, Juan. Arcipreste de Hita. Libro de Buen Amor. Jacques Joset (ed.), Madrid: Espasa-Calpe, I98I (Clásicos Castellanos).

Zumthor, Paul. La letra y la voz. Madrid: Cátedra, I989. 